\title{
Important Factors in the Cognitive Development of Children with Hearing Impairment: Case Studies of Candidates for Cochlear Implants
}

\author{
Heloisa Romeiro Nasralla ${ }^{1}$ Maria Valéria Schimidt Goffi Gomez ${ }^{2}$ Ana Tereza Magalhaes ${ }^{2}$ \\ Ricardo Ferreira Bento ${ }^{3}$
}

${ }^{1}$ Department of Audiology, Universidade de São Paulo, São Paulo, SP, Brazil

2 Department of Otorhynolaryngology, Hospital das Clínicas da FMUSP, São Paulo, SP, Brazil

3 Department of Otolaryngology, Universidade de São Paulo,

São Paulo, SP, Brazil,

Int Arch Otorhinolaryngol 2014;18:357-361.

\begin{abstract}
Address for correspondence Heloisa Nasralla, Psychologist, Department of Audiology, Universidade de São Paulo, Rua Capote Valente, $4321^{\circ}$ andar Cj. 14 Pinheiros, São Paulo, SP 05409-001, Brazil (e-mail: dhrn@terra.com.br).
\end{abstract}

\begin{abstract}
Keywords

- deafness

- child development

- cochlear implantation
\end{abstract}

\section{Introduction}

The cognitive development of children with hearing impairment is similar to that of normally hearing children, provided their innate communication capabilities are acknowledged and capitalized upon. In the case of congenital deafness, when parents are given a prenatal diagnosis, or during the first few months after birth, the parents' anguish and feelings of guilt should be addressed. Parents should be offered alternatives and support, as it is important that they accept the child as they are developing and can mourn the loss of the expected normally hearing child. Furthermore, it is vital that their relationship with the child remains spontaneous, in particular that between the mother and child, because, received

January 16, 2014 accepted

March 24, 2014

published online

June 23, 2014
Dol http://dx.doi.org/

10.1055/s-0034-1382095. ISSN 1809-9777.
Copyright (c) 2014 by Thieme Publicações License terms Ltda, Rio de Janeiro, Brazil 
as Preisler et al pointed out, ${ }^{1}$ these early bonds form the foundation of language, emotional, social, and cognitive development.

The child should be made to perceive the existence of sound, and visual contact should be encouraged, as it aids the development of orofacial reading. For this, parents should ensure rich expression of affection and abundant physical and gestural contact should be maintained. From the perspective of behavioral psychology, language is a behavior, and like any other behavior, its learning thus occurs through environmental stimuli. ${ }^{2}$ The famous psycholinguist Noam Chomsky ${ }^{3}$ proposed $(1965,1972)$ that humans have a language acquisition device that facilitates its learning. That is, we humans seem to be biologically predisposed to acquire language. This view is shared by Pinker. ${ }^{4}$

However, the most predominant perspective on language development today is a combination of two opposing views. Thus, although it is believed that children have an innate capability to learn language, ${ }^{5}$ it is also strongly suggested that their experiences play an important role in that acquisition. These social-interactive approaches, based on the theories by Piaget ${ }^{6}$ and Vygotsky, ${ }^{7}$ espouse that children's verbal development depends on the quality of their social interactions.

In fact, children and their parents decide how to develop their language, whether it is verbal or gestural. Every option involves various family, social, emotional, cognitive, neurological, and motor coordination issues.

According to Tonietto et $\mathrm{al}^{8}{ }^{8}$ subcortical development occurs during the first 3 months of life, which allows infants to suckle and sleep. Even in this early stage, it is the mother's responsibility to identify the child's desires and anxieties by, as Virole indicates, ${ }^{9}$ symbolizing and giving meaning, providing answers and nurturing. Such symbolizations will allow the child to recognize the objects in the world. Furthermore, Tonietto et $\mathrm{al}^{8}{ }^{8}$ Carpenter et $\mathrm{al}^{10}{ }^{10}$ and Tomasello ${ }^{11}$ point out that by the age of 9 or 10 months, cortical activity increases, allowing the child to have shared attention, which is important for behavior regulation. The child displays mirror behavior, as he or she is able to imitate gestures and show interest in the surrounding objects and environment. The child is capable of pointing to objects that call for his or her attention and following adults' pointing gestures. Baron-Cohen ${ }^{12}$ put forth that the absence of these characteristics indicates a developmental delay, a specific language delay, or a more serious condition such as autism, in which the absence of symbolic games is observed. In addition to the desire of communicating, understanding other people's intentions is a prerequisite for language development.

In the case of children with hearing impairment, autism may occur as a comorbidity. In addition to the importance of early diagnosis and intervention, as emphasized by Roper et $\mathrm{al}^{13}$ we see that autism may develop because of the isolation caused by the lack of the development of any form of communication. In this context, Deggouj and Eliot suggested that the autistic features might manifest later in the life of children with hearing impairment. ${ }^{14}$ Therefore, they recommended the use of progressively programmed hearing aids to help the child gradually get used to the world of sound. They reported that hearing aids are not easily accepted by these children and are often viewed as physical aggression, given their difficulty in comprehending the world. Further, Deggouj and Eliot added that indications for using a cochlear implant (CI) are limited by the child's behavioral problems, but depending on the case, CIs can also be beneficial. ${ }^{14}$ Children's difficulties in adapting to Cls are related to programming, because in addition to having to develop a different form of hearing, words are meaningless for them. Therefore, the authors stressed the importance of a slow process for programming to help the children accept the implants. Furthermore, Azema and Virole recommended great caution, ${ }^{15}$ because perceptual reality is full of emotion and is profoundly distressing. Thus, it is possible to place the implants in these children provided they are offered the opportunity to express themselves, which involves the use of sign language by both the family and the professionals.

According to Gayda and Saleh, ${ }^{16}$ hearing impairments can have an effect on the development of psychomotor, communication, and language-acquisition skills. Similarly, they can affect psychoaffective balance, time-space structuring, and, in some cases, the organization of the central nervous system and motor skills. However, the opposite may also be true. Disabilities, delays, or immaturity of the distinct functions can be recovered with overall improvement in hearing function. In fact, the pleasure of hearing, which is absent in psychic and/or hysterical deafness, and the level of anguish in autistic individuals, to a point that they do not accept being challenged by a human voice, hampers structuring, memorization, discernment, and understanding, which can be improved by the recovery of hearing in these patients.

It is very important to observe the relationship of the child within the family, noting how the family mobilizes and restructures itself around the child's deafness.

With reference to the age-related developmental pattern discussed earlier, Tonietto et al revealed that "at 4 years of age there is a peak of cortical metabolic activity" (pp.250) ${ }^{8}$ which contributes greatly to both the child's language and cognitive development. At 4 years of age the child also understands the difference between his beliefs and those of others, which strongly shows that she has the ability to conceive mental states. ${ }^{17}$ This ability, described as Theory of Mind, allows the child to consider others' beliefs and predict their behavior, which is key to adaptation and social interaction. This topic was discussed by Baron-Cohen et al in the area of autism. ${ }^{17} \mathrm{He}$ attributed this specific difficulty to autistic patients, independent of their mental level, which distinguishes them from people with other medical conditions or other types of cognitive impairments. A child with autism exhibits an inability to consider other peoples' beliefs and predict their behavior, which explains their problems in social interactions. Thus, relationships are unpredictable and incomprehensible to them. It also explains their inability to indulge in "makebelieve" play, because they do not understand what other people know, want, feel, or believe in (i.e., metarepresentation).

The primary objective of the present study was to conduct a postevaluation of $20 \mathrm{CI}$ candidates age 1 to 13 years to examine the factors that were important for their development. 


\section{Methods}

For this purpose, we conducted interviews with the parents or just the mother and used the Vineland Social Maturity Scale (VSMS) to assess the development of motor skills, socialization, communication, and daily life activities. ${ }^{18,19}$ The VSMS provides the age level of the child with reference to these skills. It can be applied to individuals up to 19 years old. In addition to the VSMS, the cognitive capacity of children age 5 years and above was assessed using the Columbia Mental Maturity Scale (CMMS). ${ }^{20}$ In addition to providing the child's mental age and IQ this scale determines the child's attention to detail and his or her ability to conceptualize. A free drawing activity was used to examine the child's level of writing, motor control of the hands, coordination in the fingers, and self-representation, including self-identification and self-esteem. In addition, the Bender Visual Motor Gestalt Test and the Pre-Bender Visual Motor Gestalt Test ${ }^{21}$ were used to assess the child's visual and motor organization of space, to explore the presence of development delay interferences, and to indicate organic neurologic impairments or increased levels of anxiety, which are indicative of emotional impairment. Finally, the pedagogical tests were used to assess school performance and alphabetization levels of these children. ${ }^{22}$ The instruments were used according to their individual merits.

\section{Results}

The 20 cases were assessed using the psychological tools appropriate to their age group. In all cases, parents were interviewed and the patients were observed in the clinic. The VSMS was used to assess the 13 patients aged between 1 year and 11 months and 4 years and 10 months, ${ }^{18,19}$ which included free drawing or activity with pencil and paper. Visual and motor organization of space was evaluated using the Pre-Bender test when possible. ${ }^{21}$ Six patients age 5 to 13 years were eligible to be evaluated using the $\mathrm{CMMS}^{20}$; however, it could be implemented on one patient only, due to the other patients' disabilities or because they did not return for the consultation. The patient who did not return for the consultation exhibited good learning abilities and was eligible to undergo the cognitive evaluation with the CMMS, but the family did not have the financial means to bring the child to the clinic repeatedly. The Bender test, ${ }^{21}$ free drawing, and the pedagogical tests ${ }^{22}$ were used with patients who were age 6 years or more.

We had 13 cases (65\%) of the sample with development expected for their age, with issues rating the physical and family dynamics. We had one absolutely normal patient, both in his development and in relation to his family, representing $5 \%$ of the sample. We had another patient with borderline development (5\%), and five patients (25\%) declined further study because of personal issues. Nine patients (45\%) between 2 years and 6 years and 2 months had fine motor problems, and $70 \%$ of them had multiple disabilities (hemiplegia, neuropsychomotor development delay, prematurity, cytomegalovirus, rubella in the mother's pregnancy, visual problems, or Usher syndrome). Of these nine patients, three had good communication, sounds, or gestures, four spoke a few words, and two had communication difficulties due to other organic matters. In addition to good sociability, shared proper attention and good communication development was observed in 8 of the 20 children. Other children who were not scored on these issues had mothers who provided little stimulation with nonacceptance of deafness and impaired communication, apart from a case that, despite belonging to this group, maintained proper relationships with their peers and good communication.

\section{Discussion}

Nine patients (45\%), all between the ages of 2 years and 6 years and 2 months, exhibited impairments in fine motor skills. Seven of these nine cases (78\%) had multiple disabilities (hemiplegia, neuropsychomotor development delay, prematurity, cytomegalovirus, rubella, or visual impairment), which could have been the cause of an impairment in the fine motor skills rather than their hearing ailment. However, Gayda and Saleh ${ }^{16}$ emphasized that hearing impairments have an impact on motor skills. Furthermore, of these nine patients, three exhibited good communication skills, either through sounds and/or gestures (indicative gestures and through sign language along with sounds). Four of them spoke a few words, and one showed good communication skills through sign language. All were classified as normal in terms of overall development. Three of them had excellent orofacial reading (ages 3 years and 8 months, 3 years and 11 months, and 5 years, respectively). Two more cases exhibited accentuated communication difficulties and interference of specific problems, including a 2-year-old child who sometimes made the sound $p a$ (interpreted as dad) but had orofacial motor problems. The other patient was 6 years and 2 months old and made sounds and spelled isolated words without sounds, did not make complete sentences, and exhibited a delay in visual and motor space organization, with indicative signs of a brain lesion. We also wish to highlight another patient who made gestures, sounds, and used sign language. The patient was very lively, but after the $\mathrm{CI}$ procedure, he became quiet, refused to talk, and only communicated through gestures, sounds, and rich drawing activity. His mother was very anxious and she did everything for her son. She received guidance with regard to this problem but she did not put it into practice. Thus, out of the nine patients, seven had good communication skills, which leads us to believe that the problems with fine motor skills were associated with their hearing disability, as described by Horn et al. ${ }^{23}$ This did not hinder communication, but affected speech. The authors predicted that this may have occurred because both speech and motor skills share the same sources of cortical processing. We aim to conduct further studies to relate these data to the development of speech in these children following $\mathrm{CI}$ intervention. According to Siegel et al, ${ }^{24}$ early motor development has proven to be a good predictor of future language development. There is a correlation between visual, motor, and cognitive development, because they are connected in the 
same brain-body system. ${ }^{25}$ Thus, there was a change in the perception of language and motor development, which are now viewed as interdependent (see - Fig. 1).

However, the emotional, cognitive, and language differentiation depended on other factors, because $70 \%$ of the sample had multiple disabilities, which was above the 30 to $40 \%$ cited range of comorbidities in children with hearing impairment. ${ }^{26}$ The rate of occurrence of comorbidities has increased with the advancement in medicine, specifically in the area of neonatology. Therefore, premature children and children with other medical conditions are found to exhibit profound hearing disabilities associated with overall developmental impairments. ${ }^{15}$ In our cases with multiple disabilities, deafness was found to occur along with hemiplegia, Usher syndrome, meningitis, cytomegalovirus and rubella infections, neuropsychomotor development delay, prematurity and visual impairment (decreased vision), serious developmental delays, and autism. As explained before, these patients also exhibited delays or problems in motor skills. For example, the patient with Usher syndrome had walking, balance, and attention impairments and problems related to the development of shared attention. However, seven of these patients had good communication skills through sounds, speech, and sign language and understood the spoken language well. All of them exhibited good sociability and/or creative maternal relationships. Moreover, they all seemed emotionally healthy. Four of these patients exhibited good

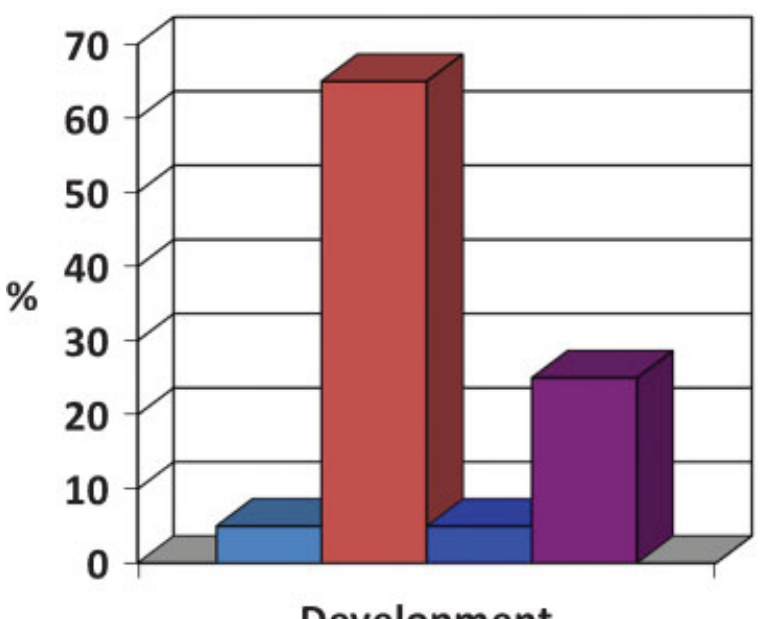

Development

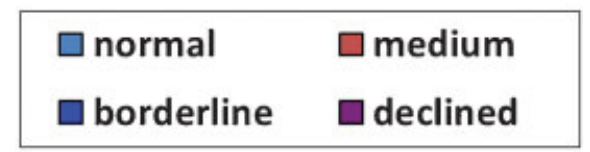

Fig. 1 Twenty cases ranged from 1 years and 11 months to 13 years. Interviews, free drawings, Vineland, Columbia, Bender, Pre-Bender, pedagogical tests were applied. Tests showed 65\% developing middle range $(n=13)$ with some compromises; $5 \%$ normal $(n=1) ; 5 \%$ borderline $(n=1) ; 25 \%$ the $\mathrm{Cl}$ was not indicated due to family members or personal difficulties $(n=5)$; $45 \%$ problems with fine motor skills, closely associated with deafness, and speech development is harmed $(n=9) .3$ vocalize, 4 of them speak, and 2 have other disabilities. sociability, whereas the other three had stimulating mothers as well. The remaining seven cases were not well developed and had communication or behavioral impairments, were overprotected, or their family dynamics were compromised. Sometimes in these cases, appropriate measures were not adopted because the children's deafness was not accepted by the parents. There were also cases in which delayed development or autism was associated with poor family structure, and the lack of assistance contributed to the maintenance of the condition.

We observed irregular development with impaired communication and speech when a child, despite having good potential, encountered environmental barriers such as poor language stimulation and/or little interaction with peers, often caused by maternal overprotection. Sociability and interaction with peers compensated for organic ailments such as delayed fine motor skills and impairments caused by comorbidities. Thus, sociability provides an escape from the limiting environment. Moreover, it offers the child an opportunity to train and stimulate the mind's creativity, imagination, and skills of theory of mind, allowing the child to understand other people's intentions and create selfconscience. Behavioral problems were also responsible for children's poor social interaction and led to low self-esteem because of the feeling of inadequacy and exclusion. Sahli and Belgin reported an improvement in self-esteem after $\mathrm{CI}$ intervention. ${ }^{27}$

In one case, financial difficulties superseded family dynamics and hindered the patient's progress. However, we also found that when the child has social opportunities, these limitations can be overcome partly, even in overprotective environments. This was especially the case with another patient, in whom good socialization was found to compensate for overprotection and delay in motor skills. This was found to happen even when the mother did not adequately stimulate the child, did not acknowledge or let the child manifest her communication potential and sign language skills, and did not value her gestures. We found that the child could still compensate for these lags through environmental stimulation and by receiving the benefits of socialization. However, social inclusion and good relationships with peers did not eliminate all problems. One child needed additional motor skills training due to delayed neuropsychomotor development. We also found that overprotection imprisons the child in a protective web and limits his or her progress.

The majority of our patients received an implant. This will allow us to verify the improvement in selective attention after the $\mathrm{Cl}$ procedure and the improvement in self-esteem in future studies. ${ }^{28}$ Nonacceptance of deafness by the mother, with explicit rejection of the child's situation, was found to be the worst factor for the child, with regard to speech, cognitive, motor, and emotional development. These observations led us to conclude that children who understand other people's intentions, feelings, and beliefs and, therefore, exhibit shared attention were those who were well stimulated by their mothers and/or had good sociability and exhibited better communication through words, gestures, and/or sounds, as 
Tonietto et $\mathrm{al}^{8}$ and Piaget ${ }^{6}$ proposed. It should be noted that a case exhibited regression in terms of contact and shared attention and did not show improvements in language.

We observed that patients without shared attention and poor communication skills were overprotected and had mothers who did not stimulate them adequately and did not accept their deafness. All these patients had poor sociability. This was also observed by Baron-Cohen et al in patients with serious development impairments and/or signs of autism. ${ }^{12}$ One case exhibited good sociability, which compensated for his problems, and showed good communication skills despite belong to this group.

\section{Conclusion}

Acceptance of the deafness of the child is the starting point for the development of communication (either verbal or gestural) and cognitive, motor, and emotional skills. Similar to Horn et $\mathrm{al}^{23}$ we observed the association between deafness and impairments in fine motor skills. Although this hindered speech development, it did not hamper communication when there was interaction with peers and maternal stimulation. Problems in family dynamics, including overprotection, accompanied by poor sociability lead to lack of independence, low self-esteem, and poor overall development in children with hearing impairment. In contrast, sociability and peer interaction compensate for organic impairments caused by comorbidities such as delayed fine motor skills and neuropsychomotor development delay. Similarly, a good child-mother relationship is a positive factor for development and for overcoming the consequences of these impairments.

\section{Summary}

We observed that impairment in fine motor skills, multiple disabilities, and an adverse family environment, such as maternal overprotection, can cause developmental delays. These are compensated for by social opportunities, in particular if the child has a stimulating mother. We will conduct further studies to observe how CIs contributes to the recovery of these same patients, as well as to the improvement of selective attention and self-esteem. We will focus on the importance of enhanced social inclusion.

\section{References}

1 Preisler G, Tvingstedt AL, Ahlström M. A psychosocial follow-up study of deaf preschool children using cochlear implants. Child Care Health Dev 2002;28(5):403-418

2 Skinner BF. Verbal Behavior. New York, NY: Appleton Century Crofts; 1957

3 Chomsky N. Syntatic Structures. Berlim1957

4 Pinker S. Words and rules in the human brain. Nature 1997; 387(6633):547-548
5 Chomsky N, Belletti A, Rizzi L. Nature and Language, with an Essay on "The Secular Priesthood and the Perils of Democracy". Cambridge, UK: Cambridge University Press; 2002

6 Piaget J. Seis Estudos de Psicologia. 24 ed. Rio de Janeiro, Brazil: Forense Universitária; 2003

7 Vygotsky LS. A formação Social da Mente. São Paulo, Brazil: Martins Fontes; 1998

8 Tonietto L, Wagner GP, Trentini CM, Sperb TM, Pimenta Parente MAM. Interfaces entre funções executivas, linguagem e intencionalidade. Paidéia 2011;21(49):247-255

9 Virole B. Psychologie de La Surdité. Bruxelles, France: De Boeck Université Publ; 1996

10 Carpenter M, Nagell K, Tomasello M. Social cognition, joint attention, and communicative competence from 9 to 15 months of age. Monogr Soc Res Child Dev 1998;63(4):i-vi, 1-33

11 Tomasello M. Constructing a Language: A Usage-Based Theory of Language Acquisition. Harvard MA: Harvard University Press; 2005

12 Baron-Cohen S, Cox A, Baird G, et al. Psychological markers in the detection of autism in infancy in a large population. Br J Psychiatry 1996;168(2):158-163

13 Roper L, Arnold P, Monteiro B. Co-occurrence of autism and deafness: diagnostic considerations. Autism 2003;7(3):245-253

14 Deggouj N, Eliot MM. Toubles du comportement de type autistique et surdité chez l'enfant. Rev Laryngol Otol Rhinol (Bord) 2005; 126(5):365-367

15 Azema B, Virole B. Appareillage et tableaux cliniques de l'enfant sourd plurihandicapé. Rev Laryngol Otol Rhinol (Bord) 1993; 114(4):293-295

16 Gayda M, Saleh D. Surdité périphérique, surdité centrale, surdité psychique: les difficultés diagnostiques chez 1'enfant autiste. Rev Laryngol Otol Rhinol (Bord) 2004;125(5):277-280

17 Baron-Cohen S, Leslie AM, Frith U. Does the autistic child have a "theory of mind"? Cognition 1985;21(1):37-46

18 Cicchetti DV, Sparrow SS, Carter A. Development and validation of a Vineland Adaptive Behavior Screening Instrument. Paper presented at: Annual Meeting of the American Psychological Association; San Francisco, CA; 1991

19 EA. A generic scale of social maturity. Am J Orthopsychiatry 1935; 5:180-188

20 Escala de Maturidade Mental Colúmbia-Casa do Psicólogo. $1^{\text {a }}$ edição. 2001

21 Bender Santucci J, Galifret G. Teste de Organização Perceptiva e Motora do Espaço de Bender e o Pré- Bender. [Prova gráfica]. In: Zazzo R, ed. Manual para exame psicológico para crianças. São Paulo, Brazil: Mestre Jou; 1968

22 Poppovic AM. Alfabetização: Disfunções psiconeurológicas. São Paulo, Brazil: Vetor; 1968

23 Horn DL, Pisoni DB, Miyamoto RT. Divergence of fine and gross motor skills in prelingually deaf children: implications for cochlear implantation. Laryngoscope 2006;116(8):1500-1506

24 Siegel LS, Saigal S, Rosenbaum P, et al. Predictors of development in preterm and full-term infants: a model for detecting the at risk child. J Pediatr Psychol 1982;7(2):135-148

25 Wilson M. Six views of embodied cognition. Psychon Bull Rev 2002;9(4):625-636

26 Berrettini S, Forli F, Genovese E, et al. Cochlear implantation in deaf children with associated disabilities: challenges and outcomes. Int J Audiol 2008;47(4):199-208

27 Sahli S, Belgin E. Comparison of self-esteem level of adolescents with cochlear implant and normal hearing. Int J Pediatr Otorhinolaryngol 2006;70(9):1601-1608

28 Marschark M, Spencer E. Deaf Studies, Language, and Education. New York, NY: Oxford University Press; 2003 